\title{
ROLE OF HIGH RESOLUTION COMPUTED TOMOGRAPHY CHEST (HRCT) IN SUSPECTED CASES OF PAEDIATRIC TUBERCULOSIS WHERE CHEST X-RAY IS NORMAL
}

\author{
Virender Singh1, Deepika Dewan², Tania Kakkar³, Manisha ${ }^{4}$
}

${ }^{1}$ Consultant Paediatrics, CHC, Katra, Jammu and Kashmir, India.

2Medical Officer, Department of Community Medicine, Government Medical College, Jammu, Jammu and Kashmir, India.

${ }^{3}$ Lecturer, Department of Obstetrics and Gynaecology, Government Medical College, Jammu, Jammu and Kashmir, India.

${ }_{4}^{4}$ Medical Officer, Department of Pathology, Government Medical College, Jammu, Jammu and Kashmir, India.

\begin{abstract}
BACKGROUND
ABSTRACT

Childhood TB contributes to a large proportion (15 - 20\%) of all TB patients in developing countries. As per National guidelines on diagnosis and treatment of Paediatric Tuberculosis in India, all efforts should be made to demonstrate bacteriological evidence in the diagnosis of paediatric TB, but difficulty in collection of sputum and due to paucibacillary primary disease in children it becomes difficult. A negative Mantoux and normal chest skiagram cannot rule out TB in a child. Better techniques like HRCT scans have advantages over conventional radiographs in diagnosing tuberculosis in paediatric patients and can detect the disease in patients whose chest radiographs are normal or equivocal.

The aim of this study is to detect pulmonary lesions in suspected cases of childhood tuberculosis, having normal or equivocal findings on chest $\mathrm{x}$-ray and to detect pulmonary lesions in patients with extrapulmonary tuberculosis.
\end{abstract}

\section{MATERIALS AND METHODS}

The present cross-sectional study was conducted over a period of one year from November 2006 to October 2007, in the Department of Paediatrics at Shri Maharaja Gulab Singh Hospital in collaboration with Department of Radiodiagnosis, Govt. Medical College, Jammu, J and K, India. Children between age groups 6 months and 18 years who were admitted in the paediatrics ward or referred from paediatric OPD suspected of tuberculosis and having normal or inconclusive chest x-rays were included in the study.

\section{RESULTS}

Out of 34 suspected patients, HRCT findings were suggestive of TB in 28 patients (82.4\%). Among them positive Mantoux, gastric lavage smear positive for AFB and lymph node biopsy diagnostic of TB were observed in 16 (57.1\%), 3 (10.7\%) and 5 (17.8\%) respectively. Sputum smear for AFB was not positive in any of these patients. Lymph nodes were present in 26 patients (92.86\%). Rim enhancement of lymph nodes, disseminated nodules (Miliary TB), consolidation (parenchymal lesions) and calcification were observed in 10, 2, 6 and 3 patients respectively. 6 out of 34 patients had normal HRCT studies. Overall, sensitivity of HRCT was reported as $100 \%$ with comparatively lower specificity.

\section{CONCLUSION}

The sensitivity of HRCT chest is quite high, as it provides additional help in improving the diagnostic accuracy as the yield of AFB is low in children and culture results are time consuming.

\section{KEY WORDS}

Childhood Tuberculosis, Chest X-Ray, High Resolution Computed Tomography, Lymph Nodes.

HOW TO CITE THIS ARTICLE: Singh V, Dewan D, Kakkar T, et al. Role of high resolution computed tomography chest (HRCT) in suspected cases of paediatric tuberculosis where chest x-ray is normal. J. Evolution Med. Dent. Sci. 2018;7(38):4234-4239, DOI: $10.14260 /$ jemds/2018/945

\section{BACKGROUND}

Tuberculosis is one of the oldest diseases known to mankind that is caused by bacteria belonging to the Mycobacterium tuberculosis complex ${ }^{1}$ and may affect any organ or tissue in the body. ${ }^{2}$ TB has remained a disease of public health importance and is responsible for heavy socioeconomic burden. India accounts for one-fourth of the global TB burden and more than $40 \%$ of the population is infected with

'Financial or Other Competing Interest': None.

Submission 04-08-2018, Peer Review 01-09-2018,

Acceptance 07-09-2018, Published 17-09-2018.

Corresponding Author:

Dr. Virender Singh,

Consultant Paediatrics,

CHC, Katra, House No. 239,

No. 9, Shakti Nagar, Jammu-180001,

Jammu and Kashmir, India.

E-mail: virta6417@gmail.com

DOI: $10.14260 /$ jemds $/ 2018 / 945$
Mycobacterium tuberculosis. ${ }^{3}$ One of the landmark achievement of 2017 is National Strategic Plan (NSP) 201725 for TB Elimination. As per the Global TB report 2017, the estimated incidence of TB in India was approximately $28,00,000 .{ }^{4}$ Despite the availability of effective preventive measures and chemotherapy, several factors including poverty, overcrowding, co-existence with HIV, population migration etc. influence the occurrence of new cases and prevalence of TB. Although, childhood tuberculosis (TB) in India is estimated to be approximately $10 \%$ of total adult incidence, only $6 \%$ of the total cases reported to the Revised National Tuberculosis Control Programme (RNTCP) are children and this proportion has remained constant. 5 Pulmonary TB remains the most common form of TB, although children suffer more from extrapulmonary forms of TB than all other age groups. However, as most private practitioners do not notify cases to the RNTCP, the overall burden of childhood TB in the country is unknown. 
Demonstration of AFB from any body fluid or tissue is confirmatory of tuberculosis. Such a proof is often lacking in childhood tuberculosis because of difficulty in collection of sputum and due to paucibacillary primary disease in children. However, studies do report that the yield of a positive test in advanced cases may be as high as in adults. Every attempt must be made to bacteriologically prove the diagnosis in every case of suspected tuberculosis.

Sputum smear examination is the primary investigation of choice, if sputum specimen is available from the child. If sputum smear is negative or not available, chest x-ray and Tuberculin Skin Test (TST/Mantoux test) are to be performed. However, a negative Mantoux cannot rule out TB in a child. ${ }^{6}$ Negative chest skiagram also does not exclude tuberculosis, because enlarged subcarinal nodes and even hilar and at times paratracheal nodes are difficult to make out in an initial chest skiagram. ${ }^{7}$

Sputum smear microscopy, often the only diagnostic test available in endemic areas is positive in less than $10-15 \%$ of children with probable TB. Sputum Culture yields are also low; reported yields in children with probable TB are less than $30-40 \% .8,9$ In addition to poor bacteriologic yields, the collection of bacteriologic specimens is often problematic. Two to three fasting gastric aspirates collected on consecutive days, usually requiring hospital admission, are routinely performed in young children who cannot cough up phlegm.

The difficulty in diagnosis has been compounded by the HIV epidemic, because other HIV associated lung diseases mimic the clinical and radiological picture of TB and the development of anergy has reduced the sensitivity of skin testing for tuberculosis. ${ }^{10}$

Better techniques would especially benefit children and infants in whom early diagnosis is imperative for preventing progressive TB. HRCT scans have advantages over conventional radiographs in diagnosing tuberculosis in paediatric patients and can detect the disease in patients whose chest radiographs are normal or equivocal. It demonstrates pulmonary architecture without superimposition of overlying structures and also depicts miliary nodules or bronchogenic nodules in the lung parenchyma, especially in patients with no evidence of nodules on the chest radiograph.11,12 It is also helpful in the distinction of active from inactive TB. HRCT finding consistent with presence of active tuberculosis was defined as presence of poorly defined nodules, tree in bud appearance, randomly distributed (Miliary) nodules, cavitations, consolidation, bronchogenic spread and pleural effusion. HRCT is highly valuable in differentiating many diseases that produce similar appearances on chest radiographs without using invasive methods to obtain material for bacteriological examination. Moreover, the delay in obtaining result from sputum culture ( 6 - 8 weeks) poses a clinical problem. The present study was an attempt to detect pulmonary lesions both in suspected cases of childhood tuberculosis having equivocal findings on chest x-ray and in patients with extrapulmonary tuberculosis.

\section{MATERIALS AND METHODS}

The present cross-sectional study was conducted over a period of one year in the Department of Paediatrics at Shri
Maharaja Gulab Singh (SMGS) Hospital in collaboration with Department of Radiodiagnosis, Govt. Medical College, Jammu, $\mathrm{J}$ and $\mathrm{K}$. The study included children between the age group of 6 months and 18 years suspected of tuberculosis who were admitted in the Paediatrics department or referred from Paediatric OPD after obtaining informed consent from their parents/guardians. Children with complaints of chronic cough and/or fever, failure to gain weight or unexpected weight loss, recurrent chest infections, short duration of fever and/or cough and fulfilling the inclusion criteria were included in the study. Detailed history regarding symptoms and contact with TB patient was recorded followed by clinical examination. Chest radiographs and tuberculin tests were performed $(0.1 \mathrm{~mL}$ of 5 TU of PPD with RT 23 and Tween 80 was injected intradermally over the anterior aspect of the forearm and the extent of induration and not erythema was read after 72 hours). Mantoux was considered positive if induration was $10 \mathrm{~mm}$ or more.

\section{Inclusion Criteria}

1. Suspected case of pulmonary TB/Extrapulmonary TB with normal or inconclusive findings on chest radiography.

2. Positive Mantoux Test.

3. Household contact known to be infected with TB or had taken ATT within past 2 years.

4. Lymphadenopathy.

A strong clinical suspicion in the absence of these symptoms was also considered as sufficient grounds for investigation.

\section{Exclusion Criteria}

1. Taking treatment for tuberculosis.

2. Had completed such treatment within the past 2 weeks.

3. Taking prophylaxis for this disease.

4. Patients suspected with CNS Tuberculosis.

HRCT chest of patients were done using the spiral CT scanner (WIPRO GE System). Patients were subjected to HRCT using $1 \mathrm{~mm}$ cuts and $10 \mathrm{~mm}$ interslice gaps. In the area of interest, inter-slice gaps were reduced. In addition to HRCT, all the patients were also subjected to work up including routine haematological work-up, sputum/gastric lavage smear was done for AFB staining (On three consecutive days, early in the morning), lymph node biopsies and other relevant investigations such as bone marrow aspiration, pleural tap and ascitic tap as and when required.

\section{Statistical Analysis}

The results were presented in percentages and proportions. Sensitivity and specificity was calculated. Significance was assessed using Chi-square test.

\section{RESULTS}

Maximum children belonged to age group of one to five years. Mean age of patients with probable TB based on HRCT was around 5.6 years (Fig. 1). Overall in the present study, there were more males $20(58.9 \%)$ as compared to females 14 $(41.1 \%)$ with male-to-female ratio of 1.4: 1 (Table 1 ). Out of 
34 patients who entered the study, HRCT positivity for probable pulmonary TB was observed in 28 patients. The most common complaints among the patients were fever and cough for more than 3 weeks followed by loss of weight/failure to thrive (FTT), loss of appetite, haemoptysis, recurrent chest infections and isolated axillary swellings. (Fig.2). Regarding clinical signs at the time of presentation, maximum patients presented with crepitations and/or wheeze followed by hepatomegaly and splenomegaly (Table2). Out of 28 patients with probable TB, lymph nodes were detected in 26 patients (92.86\%) on HRCT and in 18 patients clinically and among them eight patients were having lymph nodes of more than $1 \mathrm{~cm}$. Rim enhancement of lymph nodes, disseminated nodules (miliary TB), consolidation (parenchymal lesions) and calcification were observed in 10, 2, 6 and 3 patients respectively. The most common site of lymph nodes found on HRCT was subcarinal followed by right hilar and anterior mediastinum (Figure 3).

Multiple sites of involvement were present in 22 patients (78.57\%). Isolated subcarinal lymphadenopathy was observed in 5 patients (17.86\%) only.

Among patients with HRCT findings probable of Tuberculosis $(n=28)$, positive Mantoux, gastric lavage smear positive for AFB and lymph node biopsy diagnostic of TB were observed in 16 (57.1\%), 3 (10.7\%) and 5 (17.8\%) respectively. Sputum smear for AFB was not positive in any of these patients. Among patients with normal HRCT study, positive Mantoux was observed in two patients (33.33\%), while none of these patients showed positive gastric lavage/sputum smear for AFB or lymph node diagnostic of TB.

Among patients with probable TB based on HRCT, history of contact was present in 21 (75\%) patients and among patients with normal HRCT; history of contact was present in only 2 patients $(33.3 \%)$. The findings were statistically significant, p (<0.05). Majority, i.e. 18 (64.3\%) of probable TB patients based on HRCT findings were suffering from Protein Energy Malnutrition (PEM), out of them 4 children were suffering from grade IV malnutrition. Among patients with normal HRCT, malnutrition was found in 3 patients only.

Out of 34 patients, TB was confirmed in 8 patients (Gastric Lavage Smear positive for AFB in 3 patients and lymph node biopsy diagnostic of TB in 5 patients). All these patients had pulmonary lesions detected on HRCT scan. Sensitivity of HRCT in relation to other investigations like Mantoux test, gastric lavage and lymph node biopsy came out to be $100 \%$, while specificity was comparatively low. Since no patient with probable TB on HRCT had sputum smear positive for AFB, so sensitivity in this case was $0 \%$. Specificity in relation to combined gastric lavage smear positive for AFB and lymph node biopsy diagnostic of TB (confirmatory tests) was $23 \%$ and sensitivity was $100 \%$.

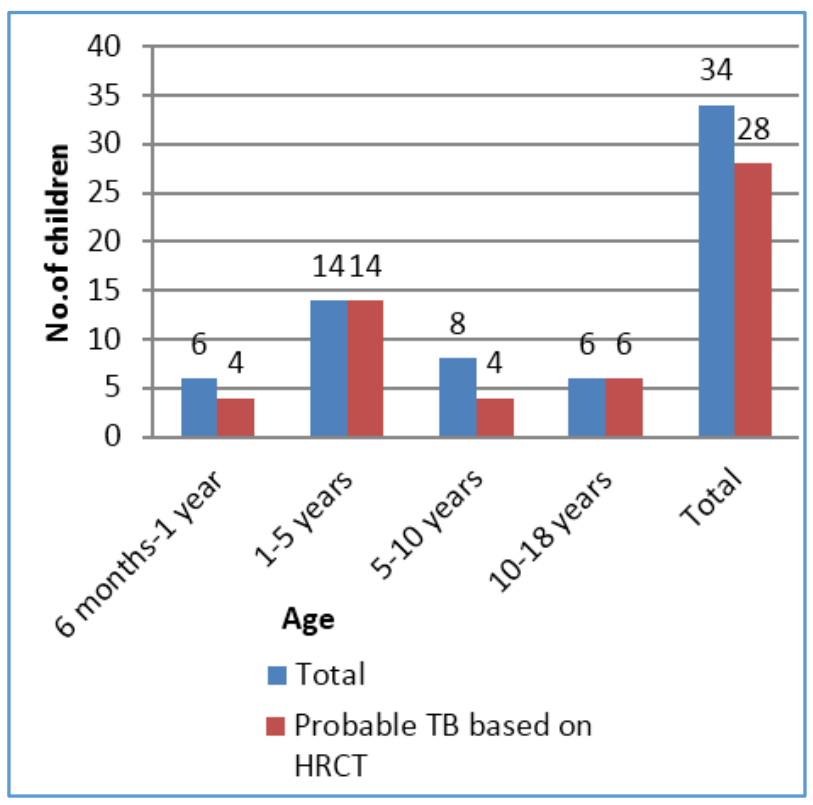

Figure 1. Age Wise distribution of Patients

\begin{tabular}{|c|c|c|c|c|}
\hline \multirow{2}{*}{ Age } & \multicolumn{2}{|c|}{ Total (n=34) } & \multicolumn{2}{c|}{$\begin{array}{c}\text { Probable TB based } \\
\text { on HRCT( } \mathbf{n = 2 8 )}\end{array}$} \\
\cline { 2 - 5 } & Male & Female & Male & Female \\
\hline $\begin{array}{c}\text { 6 months - } \\
\text { year }\end{array}$ & 4 & 2 & 3 & 1 \\
\hline 1 - 5 years & 10 & 4 & 10 & 4 \\
\hline 5 - 10 years & 4 & 4 & 2 & 2 \\
\hline 10 - 18 years & 2 & 4 & 2 & 4 \\
\hline Total & $\mathbf{2 0}$ & $\mathbf{1 4}$ & $\mathbf{1 7}$ & $\mathbf{1 1}$ \\
\hline \multicolumn{2}{|r|}{ Table 1. Sex Wise distribution of Children }
\end{tabular}

Table 1. Sex Wise distribution of Children

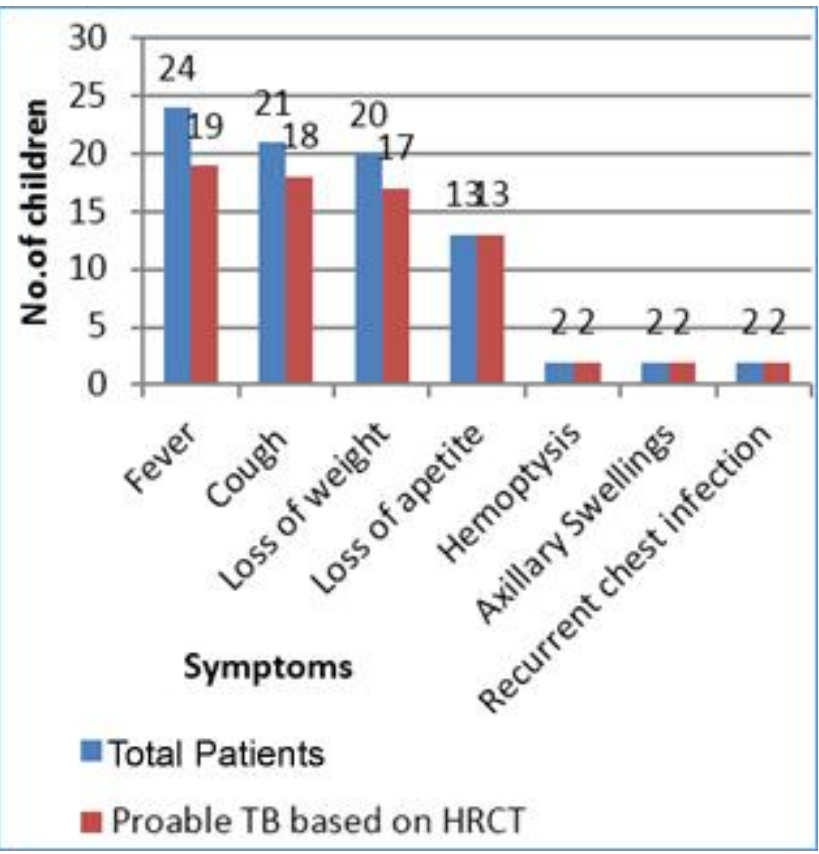

Figure 2. Presentation of Symptoms in patients with Normal HRCT and probable TB based on HRCT 


\begin{tabular}{|c|c|c|c|}
\hline Signs & & $\begin{array}{c}\text { Total } \\
\text { Patients }\end{array}$ & $\begin{array}{c}\text { Probable TB } \\
\text { Based on HRCT } \\
\text { (n=28) }\end{array}$ \\
\hline $\begin{array}{c}\text { Crepitations and } \\
\text { or Wheeze }\end{array}$ & & $24(70.6 \%)$ & $19(67.9 \%)$ \\
\hline $\begin{array}{c}\text { Hepatomegaly } \\
\text { and/or } \\
\text { splenomegaly }\end{array}$ & $22(64.7 \%)$ & $17(60.7 \%)$ \\
\hline \multirow{2}{*}{ Lymphadenopathy } & Axillary & $13(38.2 \%)$ & $8(28.6 \%)$ \\
\cline { 2 - 4 } & Cervical & $11(32.4 \%)$ & $6(21.4 \%)$ \\
\cline { 3 - 4 } & Generalised & $5(14.7 \%)$ & $4(14.3 \%)$ \\
\hline \multicolumn{2}{|c|}{ Table 2. Clinical Signs observed in Patients } \\
\hline \multicolumn{2}{|r}{}
\end{tabular}

\begin{tabular}{|c|c|c|c|c|c|c|}
\hline & \multicolumn{6}{|c|}{ Size of Lymph Nodes } \\
\hline & \multicolumn{2}{|c|}{$<0.5 \mathrm{~cm}$} & \multicolumn{2}{|c|}{$0.5-1 \mathrm{~cm}$} & \multicolumn{2}{|c|}{$>1 \mathrm{~cm}$} \\
\hline & 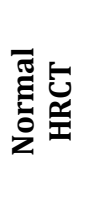 & 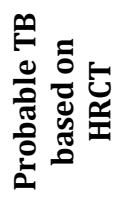 & 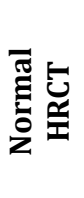 & 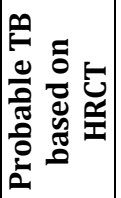 & 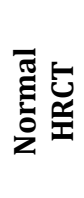 & 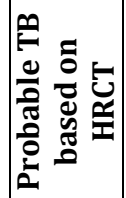 \\
\hline Axillary & 5 & 2 & 2 & 2 & 6 & 4 \\
\hline Cervical & 3 & 2 & 6 & 2 & 2 & 2 \\
\hline Generalised & 0 & 1 & 1 & 1 & 4 & 2 \\
\hline \begin{tabular}{|l|} 
Total \\
\end{tabular} & 8 & 5 & 9 & 5 & 12 & 8 \\
\hline
\end{tabular}

\begin{tabular}{|c|c|c|}
\hline Investigation & $\begin{array}{c}\text { Normal } \\
\text { HRCT }\end{array}$ & $\begin{array}{c}\text { Patients with } \\
\text { Probable TB on HRCT }\end{array}$ \\
\hline & $\mathrm{n}=6$ & $\mathrm{n}=28$ \\
\hline Positive Mantoux & 2 & 16 \\
\hline Gastric lavage smear for AFB & 0 & 3 \\
\hline Sputum smear for AFB & 0 & 0 \\
\hline LN biopsy diagnostic of TB & 0 & 5 \\
\hline ESR & 2 & 13 \\
\hline Leucocytes & 2 & 20 \\
\hline Anaemia & 6 & 28 \\
\hline Table 4. Lab Investigations of Children \\
\hline
\end{tabular}

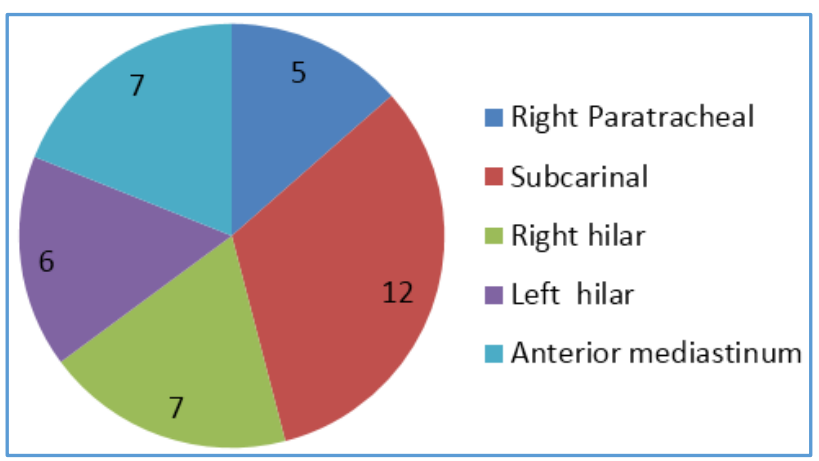

Figure 3. Distribution of Patients according to Site of Lymph Nodes

\begin{tabular}{|c|c|c|c|}
\hline & Investigation & Sensitivity & Specificity \\
\hline \multirow{7}{*}{ HRCT } & Positive Mantoux & $100 \%$ & $33.3 \%$ \\
\cline { 2 - 4 } & $\begin{array}{c}\text { Gastric lavage smear for AFB } \\
\text { diagnostic of TB }\end{array}$ & $100 \%$ & $19.4 \%$ \\
\cline { 2 - 4 } & Sputum smear for AFB & 0 & $17.6 \%$ \\
\cline { 2 - 4 } & ESR & $100 \%$ & $26.1 \%$ \\
\cline { 2 - 4 } & $\begin{array}{c}\text { Combined gastric lavage } \\
\text { smear for AFB and lymph } \\
\text { node biopsy diagnostic of TB }\end{array}$ & $100 \%$ & $23 \%$ \\
\hline Table 5. Sensitivity and Specificity of HRCT in relation to \\
Other Investigations \\
\hline
\end{tabular}

\section{DISCUSSION}

In the present study, majority (58.8\%) of patients were $<5$ years of age and mean age was 5.42 years, which corroborated with study done by Kim WS et al ${ }^{13}$ in which $52 \%$ patients were $<5$ years and mean age was 6 years. Male preponderance (M: $\mathrm{F}=1.42: 1)$ observed in present study is in concordance with the studies done by various authors. ${ }^{13,14}$ The reason may be more parental care and concern for male children.

Prolonged fever and/or prolonged cough were the most common presenting complaints in the present study observed in $70.6 \%$ and $61.8 \%$ respectively, which were similar to the observations made by Leung et al. ${ }^{15}$ In the present study 18 patients $(52.9 \%)$ had positive Mantoux, out of which 16 had positive HRCT findings, while 2 patients had normal HRCT and this was not statistically significant ( $p$ value $>0.05$ ). Tuberculin tests are unreliable in children, especially in endemic areas. ${ }^{16,17}$ Study done by Schaaf HS et al ${ }^{18}$ showed that only $41 \%$ of children with confirmed TB had positive Mantoux. The low sensitivity is attributed to anergy in children less than 2 years of age and because the reaction lags behind the radiological findings. ${ }^{18,19}$

In the present study, gastric lavage smear positive for AFB was seen in $8.8 \%$ of total patients. According to study done by American Thoracic Society and the Centres for Disease Control and Prevention, the sensitivity of acid fast stain for gastric contents is usually below $10 \% .^{20}$ Gastric aspirates have low sensitivity for mycobacterium tuberculosis, because it cannot survive acid environment and because of the low organism burden in gastric fluid. ${ }^{21}$ Hence, the diagnosis often relies heavily on imaging and a combination of clinical and laboratory findings. ${ }^{22}$ In current study, the most common site of lymph nodes found on HRCT was subcarinal (32\%) followed by right hilar and anterior mediastinum (19\%). There are contradictory reports on the incidence of lymphadenopathy in children with pulmonary TB as demonstrated by different imaging methods. Following studies reported an incidence of 90 - 98\% for mediastinal and hilar lymphadenopathy in children with Pulmonary TB using radiographs alone. ${ }^{23,24,25}$

Delacourt et al compared the findings of radiographs and CT showing that up to $60 \%$ of children with normal radiographs had lymphadenopathy on CT. ${ }^{26}$ In the same study, the authors report that $75 \%$ of children with TB anywhere in the body had a normal chest radiograph. An apparently normal chest radiograph therefore cannot exclude pulmonary TB infection in children.

Mediastinal lymphadenopathy with or without parenchymal abnormality is a radiologic hallmark of primary tuberculosis in childhood.27,28,29 In the present study with negative or inconclusive chest radiography, HRCT showed mediastinal lymphadenopathy and hilar lymphadenopathy in $75.58 \%$ and $38.23 \%$ of patients respectively. The most frequent HRCT finding in the present study was the enlarged subcarinal lymph nodes as also depicted in the study by Andronikou et al. ${ }^{14}$

The present study reported that HRCT scans delineated lymphadenopathy in 26 and miliary TB in 2 out of 34 patients. Therefore, HRCT scans can be helpful in diagnosing tuberculosis when findings of chest radiographs are normal or inconclusive. This conclusion is in concordance with study done by Katakura et al (1999) ${ }^{30}$ done on 5 children, in whom 
CT scan revealed abnormal changes including primary complexes, although chest radiographs were normal.

In our study calcification was present in $8.8 \%$ which is comparable with study done by Kim WS and Moon et al,13 where it was reported that calcification is helpful, but is present in only $15-21 \%$ of pulmonary TB patients. Harisinghani $M$ et $\mathrm{al}^{31}$ and Gulati $\mathrm{M}$ et al in their studies reported $55.85 \%$ presence of rim-enhancing nodes. However, in the present study, rim enhancement was observed in $29.4 \%$ only. The pickup rate of HRCT in detecting lesions in suspected cases of TB with normal chest radiographs was found to be $82 \%$ in our study. While in patients of TB confirmed by smear positivity for AFB in gastric lavage/ lymph node biopsy, HRCT showed positive findings in all with 100\% sensitivity.

High sensitivity of HRCT suggests it is good screening test in correctly identifying the patients with symptoms suggestive of TB who had equivocal/ non-suggestive chest $\mathrm{x}$ ray findings. However, lower specificity in relation to other diagnostic tests suggest that its discriminatory power to exclude patients without disease, i.e. true negatives is low. Hence, it fares poorly as a confirmatory test. Bacteriological confirmation remains the gold standard.

Utility of HRCT in our settings and in the present study lies in the fact that in areas with high burden of TB and limited time constraints, we cannot afford to miss even a single case of TB or delay the timely initiation of treatment as other investigations like sputum smear examination, AFB culture, Mantoux test, Gastric lavage, lymph node biopsy either are more time consuming or have poor yield in cases of Paediatric TB.

\section{Study Limitations}

Follow-up of probable TB patients (based on HRCT findings) could not be done to know the response with ATT, as our setting being government tertiary care centre caters to large population from both near and remote areas and following them was difficult due to time and resource constraints.

\section{CONCLUSION}

HRCT is a very useful imaging study in children with suspected TB with normal or inconclusive chest radiographs. The sensitivity of HRCT chest is quite high, as it provides additional help in improving the diagnostic accuracy as the yield of AFB is low in children and culture results are time consuming.

\section{ACKNOWLEDGEMENT}

To all the patients who participated in the study.

\section{REFERENCES}

[1] Raviglione MC, O’Brien RJ. Tuberculosis. In: Braunwald, edr. Harrison's principle of internal medicine. 15th edn. USA: McGraw-Hill 2001: p. 102435.

[2] Kumar V, Cortan R, Robbins S. Tuberculosis. In: Robbins, edr. Basic pathology. $6^{\text {th }}$ edn. USA: WB Saunders 1997: p. 420-5.

[3] Revised National TB Control programme. Technical and operational guidelines for tuberculosis control in India, 2016. Central TB Division. Directorate General of Health Services. MoHFW. www.tbcindia.gov.in. Accessed on 27 July, 2018.

[4] India TB Report 2018. Revised National Tuberculosis Control Programme. Annual status report. Central TB Division. Directorate General of Health Services. MoHFW. www.tbcindia.gov.in Accessed on 27 July, 2018.

[5] Central TB Division, Government of India. TB India 2014. Revised National TB Control Programme, Annual Status Report. New Delhi, India: Government of India, 2014. www.tbcindia.gov.in Accessed on 27 July, 2018.

[6] Marais BJ, Gie RP, Schaaf HS, et al. Childhood pulmonary tuberculosis: old wisdom and new challenges. Am J Resp Crit Care Med 2006;173(10):1078-90.

[7] Udani PM. Tuberculosis in children In: Parthasarathy A, edr. IAP Text book of paediatrics. $2^{\text {nd }}$ edn. New Delhi: Jaypee Brothers 2002: p. 199-214.

[8] Starke JR. Pediatric tuberculosis: time for a new approach. Tuberculosis (Edinb) 2003;83(1-3):208-12.

[9] Zar HJ, Hanslo D, Apolles P, et al. Induced sputum versus gastric lavage for microbiological confirmation of pulmonary tuberculosis in infants and young children: a prospective study. The Lancet 2005;365(9454):130-4.

[10] Shah RC. Diagnosis of Tuberculosis in children Presentation at the Fifth National Conference of Paediatric Infectious Diseases, Surat, Nov 29 to Dec 1, 2002;365:130-4.

[11] Jamieson DH, Cremin BJ. High resolution CT of the lungs in acute disseminated tuberculosis and a pediatric radiology perspective of the term "miliary". Pediatr Radiol 1993;23(5):380-3.

[12] Oh YW, Kim YH, Lee NJ, et al. High resolution CT appearance of military tuberculosis. J Comput Assist Tomogr 1994;18(6):862-6.

[13] Kim WS, Moon WK, Kim IO, et al. Pulmonary tuberculosis in children: evaluation with CT. Am J Roentgenol 1997;168(4):1005-9.

[14] Andronikou S, Joseph E, Lucas S, et al. CT scanning for the detection of tuberculous mediastinal and hilar lymphadenopathy in children. Pediatr Radiol 2004;34(3):232-6.

[15] Leung AN, Muller NL, Pineda PR, et al. Primary tuberculosis in childhood: radiographic manifestations. Radiology 1992;182(1):87-91.

[16] Andronikou S, Welman CJ, Kader E. The CT features of abdominal tuberculosis in children. Pediatr Radiol 2002;32(2):75-81.

[17] Salazar GE, Schmitz TL, Cama R, et al. Pulmonary tuberculosis in children in a developing country. Pediatrics 2001;108(2):448-53.

[18] Schaaf HS, Gie RP, Beyers N, et al. Tuberculosis in infants less than three months of age. Arch Dis Child 1993;69(3):371-4.

[19] Palmer PE. Pulmonary tuberculosis - usual and unusual radiographic presentations. Semin Roentgenol 1979;14(3):204-43. 
[20] American Thoracic Society and the Centres for Disease Control and Prevention. Diagnostic Standards and Classification of TB in adults and children. Am J Respir Crit Care Med 2000;161(4 Pt 1):1376-95.

[21] Neu N, Saiman L, Gabriel SP, et al. Diagnosis of pediatric tuberculosis in the modern era. Pediatr Infect Dis J 1999;18(2):122-6.

[22] Schaaf HS, Beyers N, Gie RP, et al. Respiratory tuberculosis in childhood: the diagnostic value of clinical features and special investigations. Pediatr Infect Dis J 1995;14(3):189-94.

[23] Lamont AC, Cremin BJ, Pelteret RM. Radiological patterns of pulmonary TB in the paediatric age group. Pediatr Radiol 1986;16(1):2-7.

[24] Correa AG. Unique aspects of tuberculosis in the pediatric population. Clin Chest Med 1997;18(1):8998.

[25] Agrons GA, Markowitz RI, Kramer SS. Pulmonary tuberculosis in children. Semin Roentgenol 1993;28(2):158-72.
[26] Delacourt C, Mani TM, Bonnerot V, et al. Computed tomography with a normal chest radiograph in tuberculous infection. Arch Dis Child 1993;69(4):4302.

[27] Effman EL. Pulmonary infection. In: Kuhn JP, Slovis TL, Haller JO, eds. Caffey's pediatric diagnostic imaging. 10th edn. Philadelphia, PA: Mosby 2004: p. 982-1039.

[28] McAdams HP, Erasmus J, Winter JA. Radiologic manifestations of pulmonary tuberculosis. Radiol Clin North Am 1995;33(4):655-78.

[29] Marais BJ, Gie RP, Schaaf HS, et al. A proposed radiological classification of childhood Intra-thoracic tuberculosis. Pediatr Radiol 2004;34(11):886-94.

[30] Katakura S, Imagawa $\mathrm{T}$, Ito $\mathrm{S}$, et al. Computed tomography with normal chest radiology in childhood tuberculosis. Kansenshogaku Zasshi 1999;73(2):1307.

[31] Harisinghani MG, McLoud TC, Shepard JA, et al. Tuberculosis from head to toe. Radiographics 2000;20(2):449-70. 